\title{
Estimation of Global Solar Radiation and Clearness Index in Coast of Gulf of Guinea, Nigeria
}

\author{
O. A. Nathaniel ${ }^{1 *}$, A. S. Oluwadara ${ }^{1}$, O. A. Joshua ${ }^{2}$, A. A. Jacob ${ }^{1}$ \\ ${ }^{1}$ Department of Physics and Solar Energy, Faculty of Science, Bowen University, Iwo, Nigeria \\ ${ }^{2}$ Department of Computer Science and Information Technology, Bowen University, Iwo, Nigeria
}

\section{$P A P E R \quad I N F O$}

\section{Paper history:}

Received 03 January 2019

Accepted in revised form 16 September 2019

\section{Keywords:}

Clearness Index

Global Solar Radiation

Gulf of Guinea Nigeria

Sunshine Hou

\section{A $B$ S $S$ T R A $A$ C $T$}

The concept of solar energy and its applications in present day would come to be one of the solutions to our Nigerian problem of instability and epileptic power supply. In this study, data for mean monthly sunshine hours and global solar radiation for Ikeja, Lagos state capital $\left(6.58^{\circ} \mathrm{N}, 3.32^{\circ} \mathrm{E}\right)$ were obtained from Nigeria Metrological Agency (NiMeT), Oshodi Lagos, Nigeria and spanned 1996 to 2010. The data for global solar radiation were measured using a Gunn-Bellani radiometer. A linear regression correlation model was developed for Ikeja and other surrounding area in south-western part of Nigeria with similar meteorological conditions. The results of estimated global solar radiation ranged from $5.1 \mathrm{MJm}^{-2} \mathrm{day}^{-1}$ on average for August and 13.1 $\mathrm{MJm}^{-2}$ day $^{-1}$ for March for Lagos. The Angstrom constants $a$ and $b$ of Angstrom-type correlation to estimate monthly average global solar radiation was estimated to be 0.25 and 0.63 respectively. The result for global solar radiation were then subjected to statistical tests [MBE, RMSE, MPE] and proved to be good estimates. The value of clearness index was also estimated to range from 0.31 to 0.59 showing Lagos as a partly clear sky city.

doi: $10.5829 /$ ijee.2019.10.03.08

\section{INTRODUCTION}

The knowledge of solar energy applications in our world has come to be a known undiminishing clean and non-noise pollution source of renewable energy. The main source of solar energy is sun. This celestial body emits electromagnetic energy determined by solar output, sun-earth positioning, latitude, time of the year and time of the day [1].

To determine the relationship between and among the atmospheric parameters has become a major concern of many meteorologist, climatologist, and physicists. This has achieved acceptance over the years as means of determining causes and effects in the atmosphere, thereby providing a hint on how to deal successfully with our environment [2]. Information on availability of global solar radiation of a given geographical location is an essential factor in developing suitable solar energy system and devices for various applications [3]. It is therefore important to consider methods of estimating the solar radiation based on the readily available meteorological parameters [4]. The development of the solar radiation database for various Nigeria locations has been an on-going task for researchers in the field for many years [5].

The monthly average clearness index and the sunshine duration for Iseyin was investigated and the clearness index which is a fraction of solar radiation at the top of the atmosphere that reaches Iseyin a city located in the south western part of Nigeria varied between 0.34 in August and 0.65 in November, with an annual average of 0.53 in a findings carried out by yusuf [6] in his research on characterization of sky conditions using clearness index and relative sunshine duration for Iseyin, Nigeria.

In a research carried out by an empirical model for estimation of global radiation from sunshine duration of Ijebu-Ode south western Nigeria it was discovered that the angstrom constants were found to be 0.18 and 0.79 with a correlation of about $89 \%$ [7]. The clearness index for the south western Nigeria is given to be 0.6 by the research carried out on the evaluation of clearness index and diffuse ratio of some locations in south western, Nigeria using solar radiation data [8]. This slight difference in the patterns may be attributed to the latitudinal difference that existing between the locations. Hence, the global solar radiation in the locations vary from $12.248-20.844 \mathrm{MJm}^{-2} \mathrm{day}^{-1}$ in Abeokuta, $12.880-21.744 \mathrm{MJm}^{-2} \mathrm{day}^{-1}$ in Ado Ekiti, 12.064-21.888 $\mathrm{MJm}^{-2} \mathrm{day}^{-1}$ in Akure, $12.600-19.224 \mathrm{MJm}^{-2} \mathrm{day}^{-1}$ in Ikeja, $12.960-22.916 \mathrm{MJm}^{-2} \mathrm{day}^{-1}$ in Ogbomoso, $12.420-21.276 \mathrm{MJm}^{-2} \mathrm{day}^{-1}$ in Osogbo. 
The clearness index $\left(K_{t}\right)$ value ranges between $0.35-0.59$ (Abeokuta), 0.36 - 0.61 (Ado Ekiti), $0.34-0.61$ (Akure), 0.32 - 0.48 (Ikeja), 0.39 - 0.61 (Ogbomoso) and $0.34-0.53$ (Osogbo). In Abeokuta, the highest $K_{t}(0.595)$ observed in January and December while the lowest $K_{t}(0.35)$ occurred in August. In Ado Ekiti, the highest value of $K_{t}(0.61)$ observed in January and December and lowest value $K_{t}(0.38)$ observed in July. Highest value $K_{t}(0.61)$ observed in Akure in January while the lowest $K_{t}(0.35)$ occurred in August. In Ikeja, highest value $K_{t}(0.58)$ observed in December and lowest value $K_{t}(0.38)$ in July. In Ogbomoso, the highest value of $K_{t}$ (0.62) observed in January and December and lowest value $K_{t}$ (0.37) observed in August [8]. In Osogbo, the highest value of $K_{t}(0.60)$ occurred in January while the lowest value of $K_{t}$ (0.34) observed in August. This indicates that the sky is very clear over Akure, Ado Ekiti, Ogbomoso and Osogbo south western Nigeria throughout the year except in June to September.

\section{METHODOLOGY}

Baseline data of monthly mean global solar radiation $(H)$ and monthly mean sunshine hour $(S)$ data for this study were obtained from the Nigeria Meteorological Agency (NiMeT), Oshodi, Lagos, Nigeria. The global solar radiation data were measured with a Gunn-Bellani radiometer. The data covered the period of fifteen (15) years spanning from 1996 to 2010 at the selected meteorological station. The data were collected in Microsoft excel spread sheet format. The yearly average of each parameter for each month of each station was computed from where the monthly average of fifteen years data was obtained for each of the stations. The results obtained from this were used to study the trends of sunshine duration and solar radiation in each station. The regression coefficient $a$ and $b, H, H_{0}, \frac{H}{H_{0}}, w_{s}, S_{0}, \delta$ were also calculated by means of simulation of the variables into Java program compatible with net beans which served as calculator for the parameters of each station. Graphical analysis were also exploited by plotting graphs of monthly mean estimated and measured global solar radiation, mean monthly sunshine hour data and mean yearly Sunshine hour data. This was done in order to make easy for the comparison of the sunshine duration and global solar radiation between the selected stations.

The original Angstrom-type regression equation that relates monthly average daily radiation to clear day radiation at any station and average fraction of possible sunshine hours:

$$
\frac{\bar{H}}{\bar{H}_{c}}=a^{\prime}+b^{\prime} \frac{\bar{n}}{\bar{N}}
$$

where $\bar{H}=$ The monthly average of daily solar radiation on a horizontal surface

$\bar{H}_{c}=$ The average clear sky daily solar radiation for the location and month

$a^{\prime}, b^{\prime}=$ Empirical constants

$\bar{n}=$ Monthly average daily hours of bright sunshine

$\bar{N}=$ monthly average of the maximum possible daily hours of bright sunshine.

Equation (1) was modified to be based on extraterrestrial radiation on horizontal surface rather than on clear day radiation:

$$
\frac{H}{H_{0}}=\left(a+b \frac{S}{S_{0}}\right)
$$

where $H_{0}$ is the radiation outside of the atmosphere subject to latitude of the location.

$$
\begin{aligned}
& a=-0.110+0.235 \cos (\varnothing)+0.323\left(\frac{s}{S_{0}}\right) \\
& b=1.449-0.553 \cos (\varnothing)-0.694\left(\frac{s}{S_{0}}\right) \\
& \frac{H}{H_{0}} \text { is the clearness index, } K_{t} .
\end{aligned}
$$

where $S$ is monthly average daily hours of bright sunshine and $S_{0}$ is monthly average of the maximum possible daily hours of bright sunshine.

$$
S_{0}=\frac{2}{15} \omega_{s}
$$

This is obtained by integrating Equation (2) over period from sunrise to sunset. If $G_{s c}$ is in watts per square metre, $H_{0}$ in Joules per square metre is

$$
\begin{aligned}
& H_{0}=\frac{24 \times 3600 G_{s c}}{\pi}\left[1+0.033 \cos \left(\frac{360 n}{365}\right)\right] \times \\
& {\left[\cos \emptyset \cos \delta \sin \omega_{s}+\frac{2 \pi \omega_{s}}{360} \sin \emptyset \sin \delta\right]} \\
& \text { where } \\
& \omega_{s}=\cos ^{-1}(-\tan \phi \tan \delta) \\
& \delta=23.45 \sin \left(360 \frac{284+n}{365}\right)
\end{aligned}
$$

The difference between estimated and measured values of solar radiation were determined by mean bias error (MBE), the root mean square error (RMSE) and mean percentage error (MPE).

\section{Mean Bias Error (MBE)}

This test helps to calculate the error or the deviation of the estimated value from the measured value and provides information on long-term performance. A low MBE value is desired. A negative value gives the average amount of under estimation in the estimated value.

$$
M B E=\frac{1}{n} \sum_{1}^{n}\left(H_{\text {cal }}-H_{\text {meas }}\right)
$$

\section{Root Mean Square Error (RMSE)}

The value of RMSE is always positive, representing zero in the ideal case. The normalized root mean square error gives information on the short term performance of the correlations by allowing a term by term comparison of the actual deviation between the predicted and measured values. The smaller the value, the better the correlation [9].

$$
R M S E=\left[\frac{1}{2} \sum_{1}^{n}\left(H_{\text {cal }}-H_{\text {meas }}\right)^{2}\right]^{1 / 2}
$$

\section{Mean Percentage Error (MPE)}

This is one of the measures used to evaluate forecasts using forecast errors. Forecast error is defined as actual observation minus forecast. The mean percentage error is the average or mean of all the percentage errors. A percentage error between $-10 \%$ and $+10 \%$ is considered acceptable [10].

$$
\operatorname{MPE}(\%)=\frac{1}{n} \sum_{1}^{n}\left(\frac{\left(H_{\text {cal }}-H_{\text {meas }}\right)}{H_{\text {meas }}}\right) \times 100
$$




\section{RESULTS AND DISCUSSION}

The sunshine hour data for Ikeja (South-western) Nigerian were optioned and the following figures were generated by means of calculations. Figure 1 shows the mean values of monthly sunshine hours for Ikeja from 1996 to 2010. The highest sunshine hour for Ikeja to be obtained in the month of February.

The month of August for Ikeja happens to be the month with the lowest mean sunshine hour recorded for the 15 years study period of 1996 to 2010. This of which can be associated with the heavy rainfall in the area during the month; thereby reducing the sunshine hour due to more absorption, reflection or scattering of solar radiation over Ikeja in this Month. Earlier we saw that Figure 1 suggested that the highest sunshine hour for North-eastern and falls in December.

Figure 2 clearly shows that year 2005 was very favourable for Ikeja as she records her highest sunshine hour under the width band of the study. Year 1996 having the lowest sunshine hour, Ikeja also had a major drop in 2004 noticeable in the above illustrated data.

Ikeja (North-western Nigeria) shows to a large extent the distribution of sunshine hour ranges from 5.7 to 6.1. The month of October to December 2005, October to December 2008 and April to December 2010 showed higher values of 7.1 to 7.8 hours of sunshine duration as shown in Figure 3.

The data showed the minimum value of sunshine hour to be recorded in the month of February 1998. The data shown

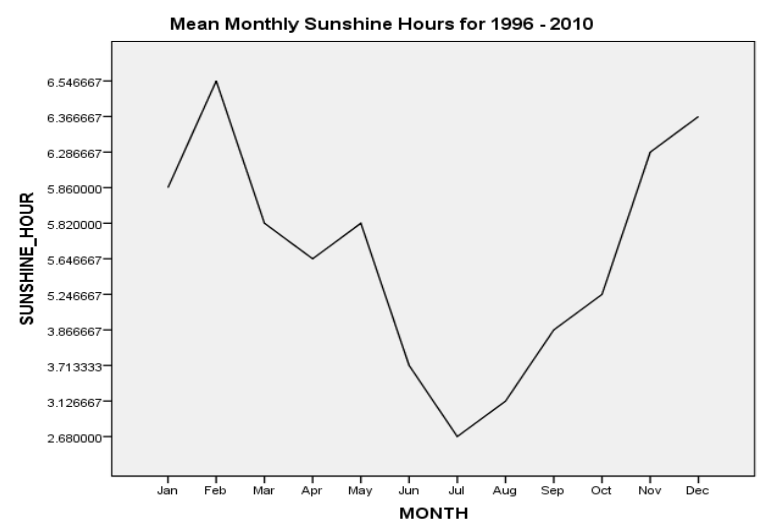

Figure 1. Mean Monthly sunshine hour for Ikeja from 1996 to 2010

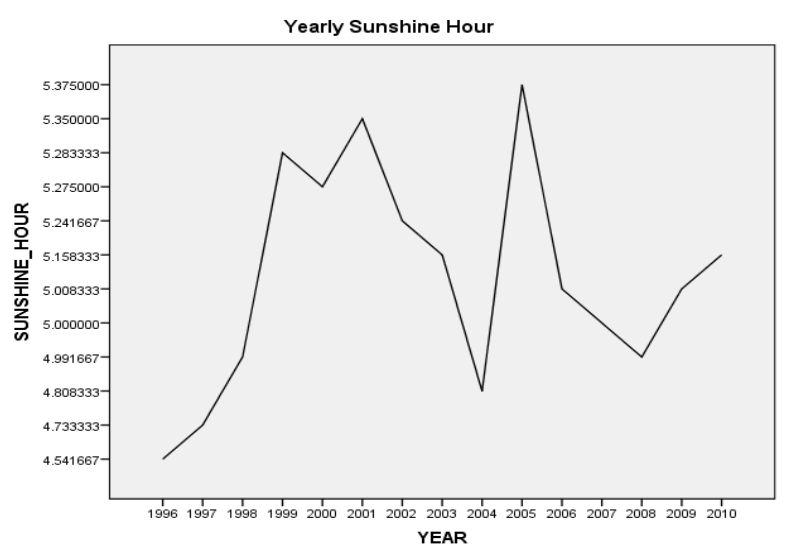

Figure 2. Mean Sunshine Hour for each year of study in Ikeja

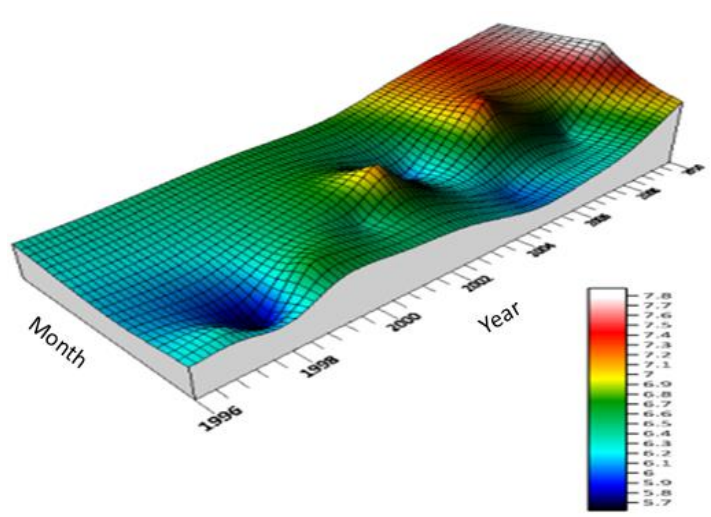

Figure 3. Distribution of Sunshine Hour for Ikeja from 1996 to 2010

in the monthly distribution along the $\mathrm{z}$ axis and the yearly distribution along the $\mathrm{x}$-axis, the distribution shows that the values for sunshine hour ranging from 5.7 to 7.8 maximum as shown by the key ranges from blue to white colour coding for the entire period of study.

The value of Angstrom constants $a$ and $b$ of Angstrom type equation for the estimating global solar radiation for Ikeja Lagos state in Table 1 during this study was averaged and presented in the following equation:

$$
\frac{H}{H_{0}}=0.25+0.63 \frac{S}{S_{0}}
$$

This equation gives an empirical model for estimating global solar radiation in Ikeja, Lagos State Nigeria and surrounding cities in the South-Western part of Nigeria. The clearness index for Lagos was estimated to fall between 0.35 and 0.59 for the period of this study.

Figure 4 shows a plot of the measures and estimated global solar radiation for Ikeja. The percentage variation between the measured and the estimated values was found to be $7.64 \%$. This value of percentage variations gives a very much correlation between the measured values and the estimated values of global solar radiation in Ikeja and by extension the South-western part of the country.

The months of February, November and December as shown in Figure 5 has clear shy as compared with June, July and August with the closest values to low cloudiness for Ikeja. Ikeja happens to have its cloud thick in July.

\section{Correlation between $\boldsymbol{H}_{\text {est }}$ and $\boldsymbol{H}_{\text {meas }}$ for Ikeja}

Figure 6 shows the correlation between estimated global solar radiation and measured global solar radiation for Ikeja. This figure shows a correlation of 0.91 between these variables. This value of 0.91 for correlation shows that the angstroms constants for estimating global solar radiation for Ikeja have a certain high degree of correctness for estimating global solar radiation. For further investigation as to why the angstrom constants for this location was high as other locations under this study, the correlation of the measured global solar radiation and these values obtained for angstrom constants was carried out and found to be 0.85 . The correlation between the measured global solar radiation for Ikeja and the values of Angstrom constants seen to agree for the estimated values of global solar radiation for this location hence; the value for angstrom constants could be used. 
TABLE 1. Estimated Monthly Global Solar Radiation, Angstrom coefficient constants, Relative Sunshine and Clearness index for Ikeja (1996 - 2010).

\begin{tabular}{|c|c|c|c|c|c|c|c|c|}
\hline Month & Mean Sunshine Hour $S$ & $H_{e s t} M J^{-2}$ day $^{-1}$ & Mean Anomaly & $H_{m e a s} M J^{-2}$ day $^{-1}$ & $A$ & $b$ & $\frac{S}{S_{0}}$ & $\boldsymbol{K}_{t}$ \\
\hline Jan. & 5.86 & 10.8 & 0.77 & 10.76 & 0.27 & 0.57 & 0.50 & 0.56 \\
\hline Feb. & 6.54 & 10.8 & 0.77 & 12.34 & 0.29 & 0.53 & 0.55 & 0.59 \\
\hline Mar. & 5.82 & 12.8 & 2.77 & 13.06 & 0.26 & 0.58 & 0.48 & 0.55 \\
\hline Apr. & 5.64 & 13.1 & 3.07 & 13.29 & 0.26 & 0.60 & 0.46 & 0.54 \\
\hline May & 5.82 & 12.7 & 2.67 & 11.94 & 0.26 & 0.59 & 0.47 & 0.55 \\
\hline Jun. & 3.71 & 11.2 & 1.17 & 10.28 & 0.20 & 0.71 & 0.29 & 0.42 \\
\hline Jul. & 2.68 & 7.6 & -2.43 & 8.14 & 0.18 & 0.77 & 0.22 & 0.35 \\
\hline Aug. & 3.12 & 5.1 & -4.93 & 7.35 & 0.19 & 0.74 & 0.25 & 0.38 \\
\hline Sep. & 3.86 & 6.9 & -3.13 & 8.95 & 0.21 & 0.70 & 0.32 & 0.44 \\
\hline Oct. & 5.24 & 8.5 & -1.53 & 10.32 & 0.25 & 0.61 & 0.44 & 0.53 \\
\hline Nov. & 6.28 & 10.2 & 0.17 & 11.81 & 0.28 & 0.55 & 0.54 & 0.58 \\
\hline Dec. & 6.36 & 10.7 & 0.67 & 12.13 & 0.29 & 0.54 & 0.55 & 0.58 \\
\hline
\end{tabular}

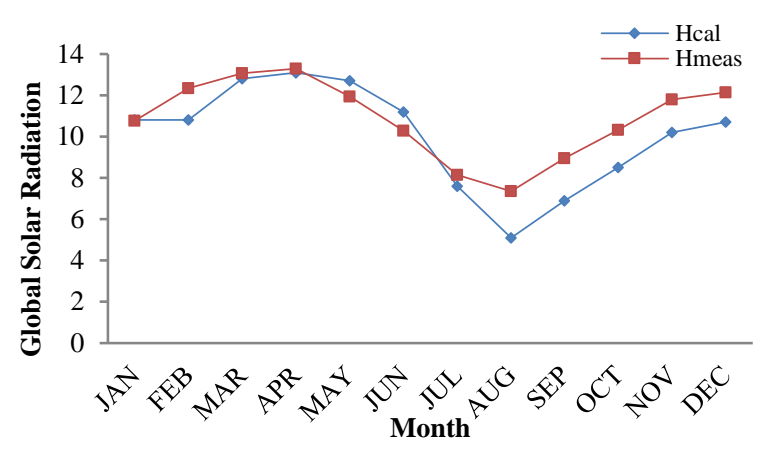

Figure 4. Monthly Estimated and Measured Global Solar Radiation for Ikeja (1996 - 2010)

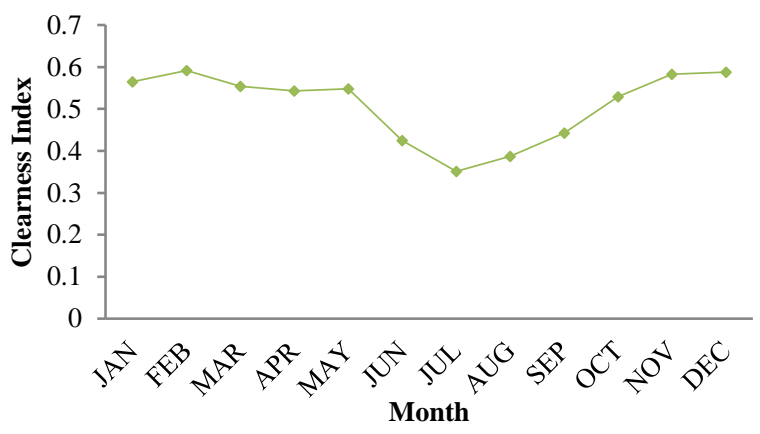

Figure 5. Monthly Estimated Clearness Index for Ikeja

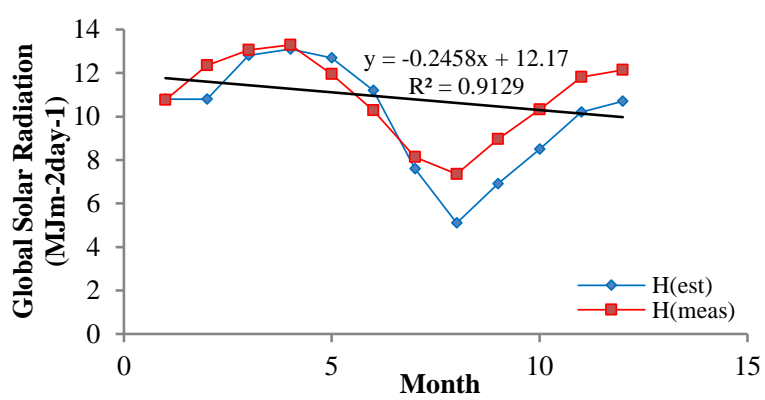

Figure 6. Correlation between estimated global solar radiation and measured global solar radiation for Ikeja

\section{Statistical test results}

Tables 2 and 3 show the statistical error result and clearness index for different locations of study, respectively.

Ikeja in this study had a Maximum clear sky index of 0.59 in February and a minimum of 0.35 in July giving an average of 0.51 clear sky conditions for the period of study for the whole months, a research carried out by Sanusi and Ojo [8] agrees with the value of 0.59 as the clearness index for south western Nigeria.

TABLE 2. Statistical Error result presentation

\begin{tabular}{cccccc}
\hline Station & $\begin{array}{c}\boldsymbol{H}_{\text {est }} \\
\mathbf{M J m}^{-2} \text { day }^{-1}\end{array}$ & $\begin{array}{c}\boldsymbol{H}_{\text {meas }} \\
\mathbf{M J m}^{-2} \text { day }^{-1}\end{array}$ & MBE & RMSE & $\begin{array}{c}\text { MPE } \\
(\boldsymbol{\%})\end{array}$ \\
\hline IKEJA & 10.03333 & 10.86722 & -0.4169 & 0.5896 & 3.83 \\
\hline
\end{tabular}

TABLE 3. Clearness index for different locations of study

\begin{tabular}{lccc}
\hline Station & $\boldsymbol{K}_{\boldsymbol{t}}(\boldsymbol{m a x})$ & $\boldsymbol{K}_{\boldsymbol{t}}(\boldsymbol{m i n})$ & $\boldsymbol{K}_{\boldsymbol{t}}$ \\
\hline IKEJA & 0.5915 & 0.3511 & 0.50875 \\
\hline
\end{tabular}

\section{CONCLUSION}

Present study concluded that while the use of fossil and carbon based fuel is becoming increasingly scarce, the knowledge of possible positive solar energy potentials in Lagos would play a major role to overcome the sole dependency on this non-renewable energy sources. This study also concluded that the clearness index of Lagos with an average of 0.51 shows Lagos as a partially clear sky area and tendency of harnessing global solar radiation is very promising.

\section{REFERENCES}

1. Salima, G. and Chavula, G.M., 2012, Determining Angstrom constants for estimating solar radiation in Malawi, International Journal of Geosciences, 3(2), pp. 391-397. 
2. Umoh, A.A., Akpan, A.O. and Jacob, B.B., 2013, Rainfall and relative humidity occurrence patterns in uyo metropolis, Akwa Ibom state, South-South Nigeria, IOSR Journal of Engineering, 3(8), pp.27-31.

3. Innocent, A.J., Jacob, O.E., Chibuzo, G.C., James, I. and Odeh, D.O., 2015, Estimation of Global Solar Radiation in Gusau, Nigeria, International Journal of Research in Engineering \& Technology, 3(2), pp.27-32.

4. Musa, B., Zangina, U. and Aminu, M., 2012, Estimation of global solar radiation in Maiduguri, Nigeria using Angstrom model, ARPN Journal of Engineering and Applied Sciences, 7(12), pp.1623-1627.

5. Ekpe, J.E. and Nnabuchi, M.N., 2012, Solar radiation in Onitsha: A correlation with average temperature, Scholarity Journals of Biotechnology, 1(5), pp.101-107.

6. Yusuf, A., 2017, Characterization of sky conditions using clearness index and relative sunshine duration for Iseyin, Nigeria. International Journal of Physical Sciences Reseach, 1(1), pp.53-60.
7. Ogunsanwo, F.O., Adepitan, J.O., Ozebo, V.C. and Ayanda, J.D., 2016, Empirical model for estimation of global radiation from sunshine duration of Ijebu-Ode, International Journal of Physical Sciences, 11(3), pp.32-39.

8. Sanusi, Y. K. and Ojo, A. M. O., 2015, Evaluation of Clearness Index and Diffuse Ratio of Some Locations In South Western, Nigeriausing Solar Radiation Data, IOSR Journal of Applied Physics, 7(5), pp.45-51.

9. Namrata, K., Sharma, S.P. and Saksena, S.B.L., 2012, Comparison of estimated daily global solar radiation using different empirical models, International Journal of Science and Advanced Technology, 2(4), pp.132-137.

10. Muzathik, A.M., Nik, W.B.W., Ibrahim, M.Z., Samo, K.B., Sopian, K. and Alghoul, M.A., 2011, Daily Global Solar Radiation Estimate Based on Sunshine Hours, International journal of mechanical and materials engineering, 6(1), pp.75-80. 